\title{
Representações do mundo da moda na mídia: do luxo ao lixo*
}

RESUMO

O presente trabalho tem por objetivo refletir sobre o papel do discurso da mídia na construção de representações contraditórias e excludentes que dizem respeito a esferas culturais que fazem parte da mesma sociedade moderna brasileira: neste caso, a pobreza e o mundo da moda. Um Estudo de Caso sobre Gisele Guimarães, moradora da Cidade de Deus e modelo de moda, e a análise de matérias publicadas em revistas e jornais brasileiros, além de um programa da TV francesa, servem de objeto de estudo para esta discussão.

\section{PALAVRAS-CHAVE}

mídia

representações culturais

identidade

\section{ABSTRACT}

The main proposition of this work is to reflect about contradictory and excludent character of the media role in the construction of social representations of cultural issues that are part of the same brazilian modern society: in this case, the poverty and the fashion world. A Study of Case studyGisele Guimarães, a fashion model from Cidade de Deus, and the analisys of newspapers and magazines articles, and also of a TV documentary from french television, all this serve as study object for the development of this discussion.

\section{KEY WORDS}

media

cultural representations

identity
Em 2008, defendi minha tese de Doutorado junto ao PPGSA - Programa de Pós-Graduação em Sociologia e Antropologia (IFCS - UFRJ). O título é Gisele da Favela: uma análise antropológica sobre a carreira de modelo e, nesta tese, discuto as regras e valores sociais que estão direta e implicitamente ligados à profissão de modelo no Brasil, analisando a construção de uma identidade feminina entre adolescentes e as representações sociais presentes em um dado padrão de corpo propagado no campo da moda e na mídia. Além disso, minha pesquisa busca demonstrar que o corpo feminino é um capital que, cada vez mais, serve a estratégias de inclusão na sociedade, as quais podem levar, especialmente para camadas mais pobres, à ascensão social.

Para tanto, apresento um Estudo de Caso onde analiso a trajetória da modelo Gisele Guimarães, moradora de uma favela do Rio de Janeiro, a Cidade de Deus, relacionando sua história de vida com o contexto social em que a mesma se dá, o que inclui sua origem social e o campo da moda (Pereira, 2008). São também analisadas matérias jornalísticas, publicadas em jornais, revistas, Internet e televisão, a partir das quais são desenvolvidas reflexões a respeito das representações sociais sobre o mundo da moda e da pobreza. O presente trabalho traz, portanto, algumas conclusões de minha tese e tem por objetivo analisar a construção das representações sociais a respeito do mundo da moda no discurso midiático e, particularmente, a representação sobre a modelo sobre a qual desenvolvi o Estudo de Caso, Gisele Guimarães. Para tanto, apresento quatro das cinco referências utilizadas na pesquisa, ou seja, uma reportagem publicada da revista brasileira Marie Claire, um vídeo exibido na televisão francesa e duas matérias publicadas no jornal Folha de São Paulo.

Gisele Guimarães, além de modelo, é também coordenadora e professora do Projeto Lente dos Sonhos, onde ensina crianças, adolescentes e jovens da Cidade de Deus, em sua maioria do sexo feminino, a desfilar na passarela, como modelo de moda.

\section{Revista Marie Claire, Brasil}

Top model do morro. Na ponte sobre o Rio Grande, na laje, em meio a uma profusão de fios elétricos. Não importa. Na Cidade de Deus, qualquer lugar é lugar para fazer moda. Por mão e obra de dois moradores da favela, onde atua o Comando Vermelho, uma escola de modelos na comunidade descobre talentos escondidos nesse universo nada fashion. E revela que ali muitos lutam sem dar tiro nenhum. (Revista Marie Claire, março de 2007, p. 38-39).

\section{Cláudia da Silva Pereira}

Professora do Departamento de Comunicação Social da PUC-Rio/RJ/BR caupereira@gmail.com 
Neste lide, que introduz a matéria de oito páginas publicada na revista Marie Claire em março de 2007, a Cidade de Deus é o lugar pobre, desorganizado e violento onde serão retratados o Projeto Lente dos Sonhos e Gisele Guimarães, além de suas alunas e de Tony Barros, fotógrafo que, como Gisele, mora na Cidade de Deus e que fundou o Projeto, em 2001. Ao lado, uma fotografia que ocupa praticamente duas páginas espelhadas mostra um dia cinza com Gisele trajando shorts jeans e camiseta branca, usando óculos escuros e cabelo preso, de braços e sorriso abertos, a despeito do cenário de fundo: muito lixo revirado em uma rua de terra, rodeada por paredes pichadas, sujas e descascadas, casas com fachadas inacabadas de tijolo ou de madeira.

\section{Na Cidade de Deus, qualquer lugar é lugar para fazer moda. Por mão e obra de dois} moradores da favela, onde atua o Comando Vermelho, uma escola de modelos na comunidade descobre talentos escondidos nesse universo nada fashion. $E$ revela que ali muitos lutam sem dar tiro nenhum

Entre aspas e assinada por Gisele Guimarães, uma frase atravessa as duas páginas, de ponta a ponta, com letras contrastantes em branco: "Tenho personalidade forte. Tudo o que faço é bem pensado. Não vou desistir'". Nas duas páginas seguintes, mais cinco fotografias: a primeira, a única em preto e branco, mostra a modelo que, juntamente com Tony Barros e Gisele, ajudou a fundar o Projeto; outras duas retratam modelos em ação; em uma quarta fotografia, Gisele atravessa descalça uma passarela vermelha, durante uma aula, sendo observada por suas alunas; na última imagem, Tony Barros está na frente de nove modelos que sorriem. Outra frase ajuda a compor esta parte da matéria: "Gisele: 'Se não fosse a moda, poderia estar casada com um bandido'".

Outra sequiência de três fotografias de modelos do Projeto ilustra a quinta e a sexta páginas, com o seguinte subtítulo: "Tony: "Quem não tem cabeça acha que entrar para o crime é solução"". Finalmente, na última parte, outras três imagens de modelos - uma delas tendo ao fundo a palavra "Paz" - e a seguinte citação, retirada da fala de uma das entrevistadas: "O mundo não vai até a Cidade de Deus pegar ninguém".

Estas três frases em destaque na matéria conduzem o leitor no sentido de que há uma fatalidade inerente ao lugar, um destino certo para quem mora na Cidade de Deus: ou se casa com um bandido, ou se entra para o crime ou se fica escondido do restante do mundo. O imaginário sobre o lugar reúne representações sobre a violência, a invisibilidade, a marginalidade e a ausência de oportunidades.

Com exceção da primeira citação de Gisele sobre sua "personalidade forte", todas as outras três não falam sobre moda ou modelos, como era de se esperar: o tema é a violência ou a Cidade de Deus. E as referências são muitas e começam logo com a primeira frase, fazendo referência a uma região chamada pelos moradores de "Santuário":

Quem entra em Cidade de Deus atrás de um santuário chega a uma barreira formada por duas rochas posicionadas para dificultar o trânsito dos veículos - em especial, carros da polícia.

O segundo parágrafo apresenta Gisele, o personagem principal da matéria, porém o tom não se desvia da violência: "Se não fosse isso, poderia estar casada com um bandido, ter engravidado ou virado prostituta".

O Projeto Lente dos Sonhos, em contraste com a fatalidade do destino dos moradores da comunidade, representa uma "luz no fim do túnel". Enfatiza-se, no texto, a história de Gisele Guimarães: apesar de morar na Cidade de Deus, ela não se envolveu com o crime e não se prostituiu. Ressalta-se a persistência de quem "não desiste nunca" de seu sonho e, mais ainda, uma "personalidade forte".

Gisele é agora identificada como uma modelo da agência Elite Models, do Rio de Janeiro, que estabelece uma ponte entre a comunidade e o mundo da moda. Mais adiante, já na próxima página, é apresentada a ONG Moda Fusion, principal parceira do Projeto e incentivadora de projetos relacionados à moda, dentro de comunidades carentes. A partir desta instituição, descobre-se que o Projeto poderá ir até Paris: "É uma sensação muito forte saber que posso ir a Paris. Se tudo der certo, preciso arrasar. Sei que essa viagem vai pesar no meu currículo" (Gisele). No dia 26 de setembro de 2006, Gisele Guimarães, Tony Barros e outras seis modelos embarcaram em uma viagem para a Bélgica e França, com apoio da ONG Moda Fusion. Além de participar da Semana de Moda de Paris, onde desfilaram em um stand do Sebrae, fizeram editoriais de moda. O tempo total da viagem somou cerca de 30 dias.

A referência ao passado de Tony Barros - "órfão de mãe, sem nunca ter visto o pai" - parece compor a história contada pela revista Marie Claire, que é de 
abandono, pobreza e desesperança. Assim como Gisele, Tony é percebido como alguém que consegue encontrar um caminho diferente de seus pares. A lembrança do primeiro ensaio fotográfico que deu origem ao Projeto Lente dos Sonhos traz de volta a temática da violência: "No dia das fotos, sem que soubessem, um cadáver surgiu no rio, debaixo da ponte".

O foco volta para Gisele nas duas últimas páginas da matéria, entremeadas por pequenas histórias de modelos - entre elas, uma adolescente que é mãe aos quinze anos e que interrompeu uma carreira que parecia promissora; e também de outra aluna, recémchegada ao Projeto. Antes de terminar, no penúltimo parágrafo, há o relato de uma sessão de fotografias em uma região conhecida como Londres e, de novo, outra referência à violência: "Logo se forma uma multidão de curiosos. Cartazes velhos da campanha para o governo do Estado estão por todos os lados - a maioria perfurada por tiros"; "Âs margens das águas opacas, camadas de lixo, crianças seminuas brincam ao léu e mães sem paciência domam os pequenos à base de palmadas".

Também a sujeira e a pobreza fazem parte da descrição do jornalista, a exemplo do relato sobre a escolha do lugar para a realização do primeiro ensaio fotográfico:

Ela se imaginou em cenas chiques, dessas que aparecem nas revistas que circulam no asfalto. Convidou Gisele, sua amiga, para posar em uma das fotos. Quando Tony soube da ideia, ofereceu uma outra: fotografar as duas, lindas e produzidas, na ponte sobre o Rio Grande, perto do santuário, na parte mais pobre, feia e suja da favela que vive sob o Comando Vermelho - grupo que controla o tráfico de drogas e armas da região.

O olhar de Tony sobre o lugar onde vive aparece: "Minha intenção era ressaltar o contraste da beleza das meninas com a degradação do lugar". Sobre a intimidade de Gisele, o texto traz descrições sobre sua casa e a situação financeira de sua família:

São quase 10 horas de um sábado ensolarado, e Gisele, usando jeans e camiseta pink, prepara uma vitamina na cozinha da casa modesta, mas impecável, onde mora com os pais - Vera, de 56 anos, empregada doméstica, e Luiz Carlos, 56 anos, vendedor de frutas em uma barraca perto dali.

Observe-se que há um contraste entre dois adjetivos que, não necessariamente, seriam opostos: "na cozinha da casa modesta, mas impecável", como se a pobreza não pudesse ser associada à limpeza.

O envolvimento de Gisele com o Projeto é representado por expressões como "ela vai se dedicar", "vai andar a pé, de van, ônibus e barco", "vai pentear, maquiar e dirigir Kate".

Tem muita menina bonita e, em geral, sou a única sarará. No asfalto, tem estrutura, as modelos de lá saem em vantagem porque chegam aos testes de cabelo e unha feitos. Aqui, as meninas mal tomam café da manhã (Gisele).

Ainda nesta entrevista com Gisele, é ressaltada a pobreza de sua família:

Quero dar uma condição de vida melhor aos meus pais e ter uma também. Durmo numa poltrona na entrada da casa, que desdobro todas as noites. As dificuldades são grandes. Às vezes bate uma desmotivação por falta de dinheiro. Mas vou em frente.

Depois de publicada a matéria, ao descrever para mim esta experiência, Gisele repete o que as páginas da Marie Claire exibiram:

Olha, eu falei pro jornalista, eu tenho personalidade forte e não vou desistir, custe o que custar, vou atrás, bater na porta e vou provar que apesar de não ter poder aquisitivo, eu tenho capacidade (Gisele).

O que é revelador é a consciência de Gisele sobre a forma como foi retratada, demonstrando que consegue manipular o discurso que se apresenta sobre sua condição de vida, como demonstra este comentário feito para mim sobre a fotógrafa que a acompanhou durante mais de uma semana:

Aí ela falou, vou fazer uma foto aqui, do lado de uma lixarada, falei, não tem lugar melhor não? Ela fez várias fotos, fiquei de chinelinho, foi uma foto descontraída (Gisele).

Gisele parece preferir que sua imagem tenha sido retratada diante de outro cenário, mas a "lixarada" é conveniente para evidenciar seu sorriso otimista e perseverante, dequem nunca desiste. Conscientemente, permite que sua personalidade sobressaia sobre sua aparência física. Ela entende, então, que sua condição de vida - pobre, violenta, impura - deixa de ser um problema e passa a ser um capital. Talvez o mais importante de todos os que acumulou até então.

O discurso da matéria da revista Marie Claire se estrutura a partir de um encadeamento de contrastes presentes nas representações, sejam elas fotográficas ou textuais, a respeito de Gisele, do Projeto e da própria Cidade de Deus.

A partir de uma interpretação das imagens, a comparação e a diferenciação estão presentes, o tempo todo. A começar pela grande fotografia de página dupla que introduz a matéria: (1) Gisele exibe sua 
alegria, tendo por trás de si o lixo e a pobreza; (2) Outra modelo, de cabelos falsamente molhados com gel, top tomara-que-caia e calça comprida brancos, e nos pés uma sandália alta também clara, faz pose sobre uma ponte de madeira que tem, na extremidade oposta, uma mulher muito pobre com duas crianças, em frente a um barraco de favela; (3) a última imagem retrata uma modelo do Projeto, esguia e exótica, sentada em cima de um balcão que está, aparentemente, nos fundos de sua casa humilde, tendo à sua volta um varal com toalhas penduradas.

\section{0 discurso da matéria da revista Marie Claire se estrutura a} partir de um encadeamento de contrastes presentes nas representações, sejam elas fotográficas ou textuais, a respeito de Gisele, do Projeto e da própria Cidade de Deus

Ao longo da leitura textual, também outras comparações levam, inevitavelmente, ao encontro de contrastes: (4) "uma escola de modelos na comunidade descobre talentos escondidos nesse universo nada fashion"; (5) "Gisele também é o elo entre a Cidade de Deus e a Elite"; (6) "um corredor direto entre comunidades carentes cariocas e o mundo da moda, das artes e do design na França"; (7)" "Procurava passar uma imagem construtiva". Mas ele também tinha que mostrar o lado realista e duro do lugar"; (8) "fotografar as duas, lindas e produzidas, na ponte sobre o Rio Grande, perto do santuário, na parte mais pobre, feia e suja da favela"; (9) "Minha intenção era ressaltar o contraste da beleza das meninas com a degradação do lugar"; (10) "o mundo não vai na Cidade de Deus pegar ninguém"; (11) "casa modesta, mas impecável"; (12) "No asfalto, tem estrutura, as modelos de lá saem em vantagem porque chegam aos testes de cabelo e unha feitos. Aqui, as meninas mal tomam café da manhã". Degradação, pobreza, desleixo, anti-moda, realidade dura, feiúra, sujeira, vida simples e carência são associações feitas diretamente à Cidade de Deus. Alegria, limpeza, elegância, talento, cultura, virtude, beleza, exotismo, fartura são referências feitas, por contraste, ao lado do "asfalto", o mundo da moda (Tabela 1).

\section{Tabela 1}

Pares de oposição: matéria da revista Marie Claire

$\begin{array}{cll}\text { (5) (10) } & \text { CIDADE DE DEUS } & \text { "O MUNDO DA MODA" } \\ \text { (1) } & \text { degradação } & \text { alegria } \\ (2) & \text { pobreza } & \text { limpeza } \\ (3) & \text { desleixo } & \text { elegância } \\ (4) & \text { anti-moda } & \text { talento para a moda } \\ (6) & \text { pobreza } & \text { cultura } \\ (7) & \text { realidade dura } & \text { virtude } \\ (8) & \text { feiúra } & \text { beleza } \\ (9) & \text { degradação } & \text { beleza } \\ (11) & \text { vida simples, humilde } & \text { exotismo, elegância } \\ (12) & \text { carência da favela } & \text { fartura do "asfalto" } \\ (13) & \text { pobreza } & \text { riqueza } \\ (14) & \text { sujeira } & \text { limpeza }\end{array}$

Gisele, como a própria matéria reforça, é o "elo" que une os dois pólos, ela é uma "intermediária". A modelo transita na favela e no "asfalto", está entre a Cidade de Deus e "o mundo" ou, mais especificamente, "o mundo da moda".

O contraste que se estabelece da primeira à última linha da matéria serve à reprodução do discurso hegemônico que coloca a beleza ao lado da moda. A matéria de Marie Claire, neste sentido, é exemplar, já que ajuda na compreensão do que se constitui o imaginário de nossa sociedade sobre a beleza feminina, representada pela moda. Beleza é associada à alegria, limpeza, riqueza, cultura, virtude e elegância. Portanto, na Cidade de Deus - um lugar pobre, degradado, violento, sujo e feio - não há espaço para a beleza.

No entanto, Gisele Guimarães sabe que seu pertencimento à Cidade de Deus é um importante capital e que, ao revelar suas origens, as comparações surgem a seu favor: mora na Cidade de Deus, mas é modelo; porque tem personalidade forte, venceu o destino de uma vida fadada ao crime e à prostituição; é pobre, porém consegue ser positiva diante da vida.

Gisele é "um elo" que liga o Projeto Lente dos Sonhos e a agência Elite; ela reside entre a cinza Cidade de Deus e a ensolarada Ipanema.

\section{Gisele da Favela: TV M6, França}

No dia 18 de março de 2007, o canal de televisão M6, da França, exibiu uma reportagem de 12 minutos sobre Gisele Guimarães. Este material serve a uma discussão sobre a maneira como se dá a construção da imagem da modelo a partir de sua origem, a Cidade de Deus. Mais ainda, suscita a uma comparação com a revista Marie Claire, já que se trata de um outro ponto de vista: o estrangeiro, o que permite uma discussão inspirada nos conceitos de Stuart Hall a respeito de identidades culturais e culturas nacionais.

Antes de iniciar a análise, porém, cabe uma breve descrição da reportagem, aqui dividida em seis partes: na primeira, as ruas da Cidade de Deus são o cenário 
que destaca seus moradores, mulheres e crianças que conversam e dançam funk para as câmeras, e também a modelo Gisele Guimarães, fotografada a céu aberto, junto com outras modelos, em meio a casas mal pintadas, esquinas com lixo exposto, contrastando com paisagens emblemáticas da cidade, como o Pão de Açúcar e a praia de Ipanema, bairro ao qual é associada a imagem da top model Gisele Bündchen. Em um segundo momento, a violência da Cidade de Deus é representada por cenas retiradas de programas jornalísticos de televisão, como invasões policiais na favela, assaltos a mão armada e o episódio do seqüestro de um ônibus da linha 174, no bairro do Jardim Botânico, que terminou com a morte de uma passageira grávida e do próprio sequestrador.

$\mathrm{Na}$ terceira parte da reportagem, Gisele Guimarães chega de táxi à agência de modelos pela qual está contratada, em Ipanema. Depois, de volta à Cidade de Deus, a modelo guia a repórter pelas ruas do lugar, conversa com adolescentes sobre as aulas de passarela, apresenta seu pai, um vendedor de frutas ambulante, mostra sua casa e fala sobre sua carreira. Na quinta parte, as imagens mostram as aulas no Projeto Lente dos Sonhos. Também nesta parte do vídeo, Gisele conversa com as adolescentes sobre maquiagem, sobre gravidez precoce e ainda sobre a beleza e sensualidade da mulher brasileira. A última parte da reportagem francesa encerra com um desfile que aconteceu na quadra da Escola de Samba da Cidade de Deus, mostrando Gisele Guimarães nervosa e chorando antes de entrar na passarela e depois, desfilando feliz e gloriosa, aplaudida pelos moradores lugar.

Há, no programa da TV francesa, aspectos que contribuem para a construção de um discurso sedimentado em representações que opõem a pobreza e o mundo da moda, a Cidade de Deus e Ipanema, o feio e o bonito, o impuro e o puro. Considerando que tal ambivalência está presente, todo o tempo, na análise do papel social de Gisele Guimarães como mediadora destes dois mundos, o da pobreza e o do mundo da moda, cabe a discussão sobre o que há de contraditório na convivência entre diversas identidades dentro de um indivíduo. Como quer Hall (2001, p. 10), há um deslocamento contínuo de identificações que permitem que o indivíduo possa lidar com a fragmentação e o "descentramento" da modernidade - o sujeito pósmoderno.

De um lado, a "miséria", além de explicitamente citada, está presente, sobretudo, nas imagens exibidas, onde as ruas são sujas, onde moradores da Cidade de Deus aparecem vestindo roupas íntimas e onde a sofisticação da moda inexiste: "Aqui, não há material sofisticado, lava-se o rosto com papel higiênico no meio da rua". O que se vê, aos olhos da reportagem, é uma condição de vida pouco civilizada. Há uma nítida separação social da favela: "Aqui tudo é mais complicado do que lá fora; e, sobretudo, mais perigoso". As cenas de violência exibidas ajudam a fixar no lugar o estigma que o persegue e que parece contagiar seus moradores: "as pessoas da favela estão habituadas a cenas de violência".

Por outro lado, a moda parece ter residência fixa em bairros ricos do Rio de Janeiro: "Até o presente momento, as top models brasileiras eram quase sempre originárias de belos bairros de regiões favorecidas, como a mais famosa delas, Gisele Bündchen, exmodelo de Dior, Calvin Klein e Dolce Gabbana".

Sendo assim, "para as que vêm das favelas, é difícil chegar à passarela" - afinal, a favela e a passarela parecem pertencer a mundos excludentes: "Pode-se dizer que os caçadores de talentos jamais se aventuram nessas comunidades quentes". Os moradores da Cidade de Deus, uma entre várias "comunidades quentes" do Rio de Janeiro, parecem, pelo vídeo, aprisionados no "aqui", um lugar "complicado" e "perigoso". "Lá fora", ao contrário, é onde vivem os "caçadores de talentos", em "belos bairros" em que moram pessoas como Gisele Bündchen.

O caso de Gisele Guimarães é exemplar no sentido de sublinhar os efeitos do discurso da cultura nacional sobre a construção de uma identidade nacional, considerando diversos aspectos como gênero, raça e classe social, assim como de uma "comunidade imaginada", conjunto de sentidos que influencia a forma como agimos e concebemos a nós mesmos (Hall, 2001, p. 50).

A comparação com a top model gaúcha confere a Gisele Guimarães uma identidade bastante particular: ela é a "Gisele da Favela" e "sua sorte foi ter sido achada, um pouco por acaso, há um ano por um agente". Por seu pertencimento a este mundo apartado da moda, somente um acaso poderia tê-la trazido para a ensolarada Ipanema, da Elite Models, a agência que "descobriu a outra Gisele, Gisele Bündchen, a top model brasileira".

Segundo a reportagem, Gisele Guimarães "freqüenta regularmente os bairros sofisticados do Rio", mas nada parece ser muito fácil para ela: "É difícil, pois não tenho dinheiro para ir ao cabeleireiro, por isso sou eu mesma que faço meu cabelo e minhas unhas. Mas eu estou aí, me viro, conheço uns truques". Se a top model é retratada em meio a ambientes glamourosos no programa francês, Gisele Guimarães parece ser uma sobrevivente. Mas é seu trabalho na comunidade que se sobressai: através dos desfiles, suas alunas têm uma esperança: "mostrar ao público que nós, as meninas da favela, temos potencial".

Gisele Guimarães, sob o olhar da televisão francesa, é mais uma "menina da favela", e não uma "top model brasileira". Ela "se espreme" com os pais em uma "minúscula casinha situada numa viela". Sua "casinha é pequena, mas tem um coração bem grande". Na vida da "Gisele da Favela", tudo parece simples demais para o sofisticado mundo da moda. Como modelo, ela 
é apenas mais uma. Afinal, "moças apenas bonitas, no Brasil há muitas".

\section{Da mesma forma que a Revista Marie Claire, brasileira, o olhar estrangeiro da TV francesa reitera uma dada "brasilidade", uma identidade nacional desigual, contrastante, paradoxal}

No entanto, a reportagem sublinha sua influência como alguém que resolveu "assumir sua situação" e tentar "escapar do destino". No panorama da televisão, surge uma Gisele preocupada com o controle de natalidade entre as adolescentes da comunidade. Ela é conselheira e divide sua experiência com suas alunas. Com o exemplo de uma aluna que engravidou aos 13 anos, as aulas de Gisele - que parece uma iniciativa isolada, já que o Projeto Lente dos Sonhos não é citado - parecem preencher um espaço na vida das meninas da favela, buscando evitar que elas sejam contagiadas pela "praga" da gravidez precoce: "E é aqui, para lutar contra essa praga que atrapalha o futuro de milhares de adolescentes no Brasil, que Gisele criou sua escola de manequins". Seu discurso é utilizado para enfatizar esta idéia: "No momento, há uma verdadeira epidemia de jovens grávidas. Outro dia, eu estava na rua, vi cinco ou seis, todas grávidas".

O Brasil que a TV francesa retrata através de Gisele Guimarães reforça a "comunidade imaginada" tal qual a construímos, contando e recontando estórias sobre a nossa nação (Hall, 2001). Da mesma forma que a Revista Marie Claire, brasileira, o olhar estrangeiro da TV francesa reitera uma dada "brasilidade", uma identidade nacional desigual, contrastante, paradoxal.

Gisele e suas alunas falam a respeito do "swing" da mulher brasileira: "As mulheres brasileiras são muito quentes. Uau! Temos uma vantagem - é o nosso rebolado incomparável, a nossa ginga bem típica". Se em um momento o documentário mostra uma Gisele preocupada com o controle de natalidade, no seguinte ela se revela sensual e provocante. É como se, por trás do discurso, prevalecesse uma irresponsabilidade inata a um ambiente pouco civilizado, como revelam estes dois comentários: "logo as meninas retomam conversas mais leves" e "mas é assim nas favelas: as pessoas faltam aos encontros, pois os problemas do dia-a-dia freqüentemente tomam o lugar dos sonhos".

Retratada pela TV francesa, Gisele Guimarães percorre universos diferentes: o primeiro, da Cidade de Deus, marcado pela violência e pela pobreza; o outro, da moda, cercado por belezas - inclusive as naturais por todos os lados e associado diretamente à imagem de Gisele Bündchen. Talvez um dos sinais que mais expressem a fatalidade do pertencimento de Gisele a um mundo pobre e de miséria é a forma como a reportagem a ela se refere: "Gisele da Favela": uma comparação óbvia com a outra Gisele, a top model.

\section{Cinderela do lixão}

Em outubro de 2007, o jornal Expresso, do Rio de Janeiro, publicou uma matéria de página inteira sobre a trajetória de Gisele Guimarães e sua viagem a Paris, da qual a modelo acabava de retornar. Ao lado desta matéria, o jornal incluiu uma nota que relembrava o caso da modelo Cristiane Andrade, comparando-a com a história de Gisele:

Cris Andrade, a musa que veio do lixão. A história de Gisele se parece com a de Cris Andrade, descoberta num lixão de Caxias, quando a atriz Giovanna Antonelli gravava cenas de sua personagem Bárbara na novela "Da cor do pecado", em 2004. A partir dali, a catadora de lixo virou modelo e chegou a desfilar no Fashion Rio, na sua estréia nas passarelas.

Deste dia em diante, a vida de Cris mudou radicalmente. Ela foi contratada por uma agência de modelos, se mudou para São Paulo (onde ainda vive) e não demorou muito para passar por uma transformação: se submeteu a uma cirurgia de implante de $200 \mathrm{ml}$ de silicone, além de lipoaspiração na barriga, pernas e glúteo. Tudo pago por um programa que promovia mudanças estéticas.

"Daqui a 20 anos vou olhar para trás e saber exatamente o que aconteceu. Foi o melhor ano da minha vida - disse, na época" (Jornal Expresso, 20 de outubro de 2007).

Meses antes, a matéria " "Cinderela do Lixão" não virou princesa" (Folha de São Paulo, 2007) conta a história de Cristiane de Andrade, que em 2004 ficou famosa por "ter sido descoberta" pela atriz Giovanna Antonelli, durante gravações de uma novela, enquanto catava lixo em um depósito no Rio de Janeiro. Esta matéria publicada no jornal Folha de São Paulo chama a atenção pela forma como a mídia trata o assunto. A associação feita entre a modelo e sua origem pobre e do "lixão" parece semelhante à maneira como a própria Gisele Guimarães vinha sendo retratada pelas revistas. Pretendo aqui desenvolver o argumento de que o discurso da mídia contribuiu para a construção da imagem de Gisele Guimarães a partir de classificações 
que opõem a pobreza e o mundo da moda.

A partir do texto que conta a vida de Cristiane, é possível encontrar aproximações e distanciamentos que reiteram a oposição entre as noções de "puro" e "impuro". A começar pelo próprio título: "Cinderela do lixão" não virou princesa". De um lado, o lixo e a então catadora; do outro, o "mundo da moda" e as promessas na carreira de modelo, onde poderia ter se tornado uma top model, ou uma princesa. A realidade pobre de Cristiane é diretamente associada ao lugar onde trabalhava, catando lixo, e de onde retirava seu rendimento. A exemplo de outras histórias sobre modelos, Cristiane teria sido "descoberta", o que ressalta a inusitada presença de uma mulher de boa aparência em um lugar como o lixão. Cristiane estaria, portanto, em um lugar ao qual não pertencia. Da mesma forma, morava em uma "favela de Bangu", mas, ao ser "descoberta", foi levada para um "flat muito chique" que, ao que tudo indica, parecia ser o lugar mais apropriado para ela.

Ao se criar a distância, ou um estranhamento, entre Cristiane e o lixão, está-se também criando uma distância entre ela e outras pessoas, catadoras de lixo. Ela foi retirada de uma situação inadequada para outra mais adequada, graças à sua beleza. Não se trata de retirar uma pessoa de condições de trabalho consideradas desumanas, mas sim de "descobrir", em meio ao lixo, uma exceção.

A carreira da ex-catadora como modelo, porém, não foi bem sucedida. Apesar da rápida fama conquistada na mídia, tudo indica que não conseguiu se firmar na profissão, como noticiado no jornal. A decisão de Cristiane foi a de não voltar para a favela e, segundo o jornal, passou a trabalhar em um restaurante, como garçonete.

Ao "largar tudo", Cristiane escolheu um caminho diferente de outras "meninas que cheiravam para emagrecer". Em contraste, na história da ex-catadora aqui analisada, exaltam-se as dificuldades por que passou:

Não que a vida no lixo fosse fácil. Seu corpo era marcado por cacos de vidro e pedaços de ferro em que esbarrava na montanha de restos. Um dia, achou dois fetos abortados em um pote. Era vida dura, mas que em matéria de cenas deprimentes, não deixava a desejar aos bastidores da moda.

Neste momento, o discurso da mídia aproxima o lixo dos "bastidores da moda", o que associaria ambos à noção de "impureza". Tanto os "fetos abortados no pote" como "as meninas que cheiravam" são cenas tomadas como "deprimentes" e "duras". Cristiane, ao contrário, é vinculada a valores positivos - portanto, "puros" - que não se corromperam por promessas.
Por esforço próprio, conseguiu ser garçonete, o que é reconhecido, no jornal, como uma "evolução": " "Ela virou garçonete? Fico feliz em saber. Ela veio do lixão, acho que progrediu muito", diz Eli Hadid" (dono da agência Mega Models).

Cristiane, que "veio do lixão", conseguiu "progredir" ao sair dele. Como garçonete, conquistou "uma vida melhor". Mas, com sugeriu o título, ela "não virou uma princesa". Para tanto, precisaria ter se transformado em modelo, o que não conseguiu, apesar de muito esforço, já que "largou tudo". Cristiane "progrediu", mas não "virou" modelo. Sua transformação foi, portanto, interrompida e seus objetivos só em parte foram conquistados.

\section{0 puro e 0 impuro nas aparências: o que dita a moda?}

Eu fiquei 3 meses sem quebrar o barraco,

Sou feia, mas tô na moda, tô podendo pagar hotel pros homens isso é que é mais importante. Quebra meu barraco.

"Sou feia, mas tô na moda" (Tati Quebra Barraco)

O jornal Folha de São Paulo, em 2004, acompanhou a presença de Tati Quebra Barraco na São Paulo Fashion Week e sua apresentação em uma boate freqüentada por "amantes de moda, música eletrônica, electro e champanhe". De acordo com a matéria jornalística, é inusitado o sucesso de Tati e de suas músicas pornográficas junto a este público, "afinal, como uma "favelada, preta, pobre e polêmica" conquistou poder a ponto de atrair o fascínio do mundo "moderno" que orbita nestes dias em torno da São Paulo Fashion Week?"

\section{o principal esforço da presente análise é mostrar que os favelados, representados aqui por Gisele, Cristiane e Tati Quebra Barraco, transformam em capital o que os estigmatiza, ressignificando sua condição de vida a favor de uma} promoção social

Convidada pela grife Cavalera, um dos destaques do evento de moda, a cantora apenas assistiu à exibição 
da coleção de roupas: o jornal a classificou como uma "figura de decoração", já que ela não desfilou e nem cantou.

A forma como o jornal se refere ao episódio de Tati Quebra Barraco em São Paulo enfatiza o grande interesse da mídia pelo contraste entre os pobres da favela e os modernos da moda. O encontro destes dois extremos, a exemplo do sucesso da funkeira da Cidade de Deus dentro de uma boate sofisticada paulistana, reitera a idéia de que a reprodução dos padrões da moda conta com a fundamental colaboração de um dado discurso jornalístico que coloca em lugares opostos os favelados (pretos, pobres e polêmicos) e os modernos (amantes da moda). Mas o principal esforço da presente análise é mostrar que os favelados, representados aqui por Gisele, Cristiane e Tati Quebra Barraco, transformam em capital o que os estigmatiza, ressignificando sua condição de vida a favor de uma promoção social. Segundo Hall (2001), tal movimento é o deslocamento das identidades, inerente à modernidade.

Douglas (1991) afirma que a natureza do impuro está em sua associação com a desordem, ou com algo que ainda está "fora de seu lugar", que foi "rejeitado" ou que está "fragmentado", ameaçando a "ordem das coisas".

Enquanto Gisele for diretamente associada à sua origem, a Cidade de Deus, representará o papel do que está fora do lugar, sem integração com o que é legitimado como belo e "puro". Gisele Guimarães, por ser da Cidade de Deus, não poderia ser considerada representante legítima da beleza. Na condição de "impura", e "perigosa", deve ser afastada de sua origem social. Neste processo, colabora sobretudo a mídia, a um só tempo marcando vínculos como as origens sociais e rompendo com eles, ao afirmar que uma "descoberta" pode levá-la a um outro mundo, ao "mundo da moda".

O que há de especial no caso de Gisele Guimarães é que se torna muito mais improvável que se consiga desvincular sua imagem do seu lugar de origem. Gisele, no discurso da comunidade, da mídia e dos profissionais diretamente ligados a ela, é indissociável de sua origem social, pois é nela que reside um de seus principais capitais: o Projeto Lente dos Sonhos na Cidade de Deus. Ao se confundir com esta causa social, Gisele deixa de parecer "fora do lugar" e, consequentemente, deixa de representar a "impureza" e o "perigo". O Projeto Lente dos Sonhos na Cidade de Deus operou uma espécie de transmutação que anulou o que havia de "impuro" em sua origem social. $\mathrm{Na}$ condição de líder de um projeto social, inverte as posições e atribui a ideia de impureza ao "mercado sujo da moda": "Eu quero ir pro mercado, sei que é um mercado muito sujo, sei que, tipo assim, $\mathrm{N}$ sujeiras, mas é um mercado que eu gosto e que está relacionado à minha pessoa" (Gisele).
Gisele reivindica para si valores positivos, submetendo-se a uma espécie de processo de "purificação" que leva em consideração desde mudanças físicas e de atitude, até escolhas seletivas dentro do meio em que vive. Ela busca sair de um estado de "impureza" e entrar em outro, de "pureza".

Como "favelada" da Cidade de Deus, Gisele Guimarães reconhece o interesse da moda e da mídia naquilo que representa para a reprodução dos padrões hegemônicos estéticos e de comportamento dos "modernos". Assumindo sua origem social e a identidade que lhe é imposta, Gisele conscientemente contribui para evidenciar o contraste entre o seu mundo e o mundo da moda. Como uma "figura de decoração", exibe-se diante de olhos encantados com uma inusitada pureza, cercada de perigo por todos os lados Famecos

\section{NOTAS}

* Comunicação apresentada na Compós 2009 - GT “Cultura das Mídias".

\section{REFERÊNCIAS}

A Europa se curva à Cidade de Deus. Expresso. 20 out 2007. Geral. p. 3.

"Cinderela do lixão" não virou princesa. Folha de São Paulo. 10 jun. 2007. Cotidiano. C8.

DOUGLAS, Mary. Pureza e Perigo: Ensaio sobre as noções de poluição e tabu. Coleção Perspectivas do Homem. Lisboa: Edições 70, 1991.

HALL, Stuart. A identidade cultural na pós-modernidade. Rio de Janeiro: DP\&A, 2001

PEREIRA, Cláudia da Silva. Gisele da Favela: Uma análise antropológica sobre a carreira de modelo. 2008. Tese (Doutorado) - UFRJ/IFCS, 2008.

Sou feia, mas tô na moda. Folha de São Paulo. 20 jun. 2004. Ilustrada. E4.

Top model do morro. Marie Claire, São Paulo, n. 192, p. 39-45, mar. 2007.

\section{Vídeos}

66 Minutes. Produção do canal M6. Paris, 18 de março de 2007. DVD (12 min.) 